\title{
Characterization of Rice Starch- t- Carrageenan Biodegradable Edible Film. Effect of Stearic Acid on the Film Properties
}

Authors:

Rahul Thakur, Bahareh Saberi, Penta Pristijono, John Golding, Costas Stathopoulos, Christopher Scarlett, Michael Bowyer, Quan Vuong

This is the accepted manuscript @ 2016, Elsevier Licensed under the Creative Commons Attribution-NonCommercialNoDerivatives 4.0 International (CC BY-NC-ND 4.0): http://creativecommons.org/licenses/by-nc-nd/4.0/ (cc) EY-NC-ND 


\section{Characterization of Rice Starch- t-Carrageenan Biodegradable Edible Film. Effect of}

\section{Stearic Acid on the Film Properties.}

3 Rahul Thakur ${ }^{a^{*}}$, Bahareh Saberi a , Penta Pristijono a , John Golding a, c, Costas Stathopoulos ${ }^{\mathrm{b}}$,

4 Christopher Scarlett ${ }^{\mathrm{a}}$, Michael Bowyer ${ }^{\mathrm{a}}$, Quan Vuong ${ }^{\mathrm{a} *}$

5 a School of Environmental and Life Sciences, University of Newcastle, Ourimbah, NSW 2258,

6 Australia

$7 \quad$ b Division of Food and Drink, School of Science, Engineering and Technology, University of 8 Abertay, Dundee DD1 1HG, UK

$9 \quad{ }^{\mathrm{c}}$ NSW Department of Primary Industries, Ourimbah, NSW 2258, Australia

$10 *$ Correspondence to:

11 R. Thakur

12 E mail: Rahul.thakur@uon.edu.au

13 School of Environmental and Life Sciences, Faculty of Science and Information Technology, 14 University of Newcastle, Brush Road, Ourimbah, NSW 2258, Australia.

15 Q. V. Vuong

16 School of Environmental and Life Sciences, Faculty of Science and Information Technology,

17 University of Newcastle, Brush Road, Ourimbah, NSW 2258, Australia.

18 E mail: vanquan.vuong@newcastle.edu.au 


\section{Abstract}

24

The main aim of this study was to develop rice starch (RS), l-carrageenan (1-car) based film. Different formulations of RS (1-4\%, w/w), t-car $(0.5-2 \%$, w/w) was blended with stearic acid (SA; $0.3-0.9 \%, w / w)$ and glycerol $(1 \%, w / w)$ as a plasticizer. The effect of film ingredients on the thickness, water vapour permeability (WVP), film solubility (FS), moisture content (MC), colour, film opacity (FO), tensile strength (TS), elongation-at-break (EAB) of film was examined. Interactions and miscibility of partaking components was studied by using Fourier transform infrared spectroscopy (FT-IR) and X-ray diffraction (XRD). Hydrocolloid suspension solution of mix polysaccharides imparted a significant impact $(\mathrm{p}<0.05)$ on the important attributes of resulting edible film. TS and EAB of film were improved significantly $(\mathrm{p}<0.05)$ when $\mathrm{t}$-car was increased in the film matrix. Formulation $\mathrm{F} 1$ comprising $2 \% \mathrm{t}$-car, $2 \%$ RS, $0.3 \%$ SA, Gly $30 \% \mathrm{w} / \mathrm{w}$ and $0.2 \%$ surfactant (tween ${ }^{\circledR 20}$ ) provided film with good physical, mechanical and barrier properties. FT-IR and XRD results reveal that molecular interactions between RS-1-car have a great impact on the film properties confining the compatibility and miscibility of mixed polysaccharide. Results of the study offers new biodegradable formulation for application on fruit and vegetables.

Keywords: Biopolymers; Biodegradable; Edible film. 


\section{Introduction}

47 Edible film and coatings are the future of packaging industries. Ability of edible biopolymers to reduce the serious environmental concerns by minimizing the usage of plastic packaging has provided the solution for many packaging issues. Hence it is important to explore the potential of natural biopolymers for the shelf life extension of fresh produce.

Starch is a complex polysaccharide biopolymer and a material of choice for the development of edible films. Due to low cost and good film forming properties it is often used in the blending combinations with other biopolymers to develop a strong film with improved properties. Composite matrices with different blending combinations have been reported to have desirable functional properties by combining the advantage of each component while overcoming their potential limitations [1]. Combinations of polysaccharides with high molecular weight compounds have provided excellent miscibility and interactions with improved mechanical properties [2]. However, detailed study is required to understand the mechanism of interactions influencing the physical, mechanical and barrier properties of film.

ı-carrageenan is water soluble biopolymers [3] extracted from certain species of red seaweed of the family Rhodophyceae. The hydrophilic linear sulphated galactan constitutes alternating galactopyranosyl units linked by $\beta(1 \rightarrow 4)$ and $\alpha(1 \rightarrow 3)$ glycosidic bonds. Commercially -cars are classified in to three different types: kappa $(\kappa)$, iota $(1)$ and lambda $(\lambda)$-1-carrageenan where $\mathrm{OSO}_{3}{ }^{-}$group numbers configuration defines the rheological properties of these sulphated compounds [4].

High flexibility and low WVP are the desired properties of edible films which are achieved by using plasticizers. Glycerol is the most commonly studied plasticizer with starch based edible coatings. [5]. However being hygroscopic, it affects the permeability properties of film while providing it flexibility [6, 7]. Fatty acids, due to their hydrophilic and hydrophobic nature have 
also been studied as plasticizers [8]. Hydrophobic substances (fatty acids, waxes and oils) in combination with other components are helpful in controlling the permeability properties of edible films. Stearic acid, palmitic acid, essential oils are most widely used plasicizers in the edible coatings currently [9].

Other components with potential capacity to improve film properties are surfactants. These are amphiphilic compounds used to improve the wettability and adhesion of film [10] and act as a emulsifiers. The hydrophobic tail of a surfactant affect the mechanical properties of starch film [11].

Improving the preservation efficiency of edible films by tailoring the mechanical and barrier properties have been conducted by using different formulations of biopolymers-ingredients combinations for instance, tapioca starch-protein [12], rice starch-lipid [13], pea starchcellulose [14], manioc starch-gelatine [15], and yam starch-cassava starch [16].

However, to the best of our knowledge no attempt has been made to study the characterisation of edible film based on rice starch-ı-carrageenan formulations. The aim of this work was, therefore, to develop rice starch, $\mathbf{t}$-car and steric acid based edible film, evaluate the effect of interactions at different ratios of ingredients on the properties of developed film. Fourier transform infrared spectroscopy (FT-IR) and X-ray diffraction (XRD) was used to highlight the interactions and miscibility between polymer-polymer and polymer with other ingredients.

\section{Material and Methods}

\subsection{Materials}

Rice grains (Oryza sativa, $c v$ Doongara) were obtained from Sunrice (Sun Rice, Leeton Australia). $\mathrm{HCl}, \mathrm{NaOH}$ were purchased from Merck Pty Ltd, Germany. Acetic acid, stearic 
93 Finechem Pty. Ltd, Australia and used as a plasticizer. The 1-car (Chondrus crispus) was

94 purchased from Melbourne Food Ingredient Depot, Australia.

95

96

97

98

99

100

101

102

103

104

105

106

107

108

109

110

111

112

113

114

115

116

\subsection{Extraction of starch}

Starch was extracted following a previously developed method [17] with some modifications.

Rice grains were steeped overnight and then grounded at low speed for 5 min using a multi blender. The slurry was filtered through the muslin cloth and centrifuged at $2000 \times \mathrm{g}$ for 10 min using Beckman coulter, Allegra X-15R centrifuge. The supernatant was collected and washed five times with excess $0.1 \mathrm{M} \mathrm{NaOH}$ to completely remove any proteins. Resultant slurry was mixed with water and filtered through $125 \mu \mathrm{m}$ and $63 \mu \mathrm{m}$ pore size sieves. The mixture was dried at $50^{\circ} \mathrm{C}$ for $48 \mathrm{hrs}$ and finally ground into powder and stored at a dry place for the further experiments.

\subsubsection{Physiological analysis of starch}

Content of proteins, moisture, ash and fat of the rice starch was determined according to AOAC methods AOAC (1990). Content of amylose in the rice starch was analysed using iodine colorimetric reaction as reported previously [18].

\subsection{Polysaccharide suspension solution}

Polysaccharide suspension solution was prepared from rice starch, -car, fatty acid, glycerol and tween ${ }^{\circledR} 20$ as shown in Table 1 . Gelatinization of rice starch was obtained by mixing rice starch (2-4\%) with water at $85^{\circ} \mathrm{C}$ for $15 \mathrm{~min}$. The $\mathrm{t}$-car $(0.5-2 \%)$ was added and heated at $80^{\circ} \mathrm{C}$ to a clear solution. Starch-ı-car mixture was then mixed and stirred with melted stearic acid (0.3-0.9\%) and $0.2 \%$ of tween ${ }^{\circledR} 20$. Finally, glycerol was added and stirred for $15 \mathrm{~min}$. To prepare the film, $20 \mathrm{ml}$ of mixture solution was poured in to petri plates and dried in oven for 24 hrs at $35^{\circ} \mathrm{C}$. Films were peeled off and conditioned at $27^{\circ} \mathrm{C}$, relative humidity (RH) $60 \%$ for 72 hrs prior to testing. 
SP and LA was determined by previously developed method [19] with some modifications.

119 Starch suspension solutions in different ratios (RS: 1 -car -2:2\%, 2.5:1.5\%, 3:1\%,4:0.5\%, pure$1204 \% \mathrm{RS}$ ) were heated in water bath at $90^{\circ} \mathrm{C}$ for $5-30 \mathrm{~min}$. Suspension solution was cooled in 121 ice before centrifugation at $15000 \mathrm{rpm}$ for $30 \mathrm{~min}$. Supernatant was used for LA determination using iodine colorimetric method [20]. LA was calculated by dividing the amylose content in supernatant to original weight of starch. Residue was weighed and dried at $110^{\circ} \mathrm{C}$ for $24 \mathrm{hrs}$ for SP determination and calculated by ratio of wet weight of residue to its dry weight.

\subsection{Film Characterisation}

\subsubsection{Physical Properties}

\subsubsection{Film thickness (FT)}

FT was measured using a digital micro-meter (Mitutoyo, Co., Code No. 543-551-1, Model IDdifferent points for individual film samples and average value was calculated. Results from thickness measurement were used to assess the water vapour permeability and opacity of edible 132 film.

\subsubsection{Film solubility (FS)}

134 FS was measured according to previously reported method [21] with some modifications. Film 135 strips (15 x $50 \mathrm{~mm}$ ) were placed in $50 \mathrm{ml}$ of distilled water with subsequently shaking at 30 rpm for 24 hrs at room temperature. Undissolved portion was then collected and dried at $110^{\circ} \mathrm{C}$ for 24 hrs to a constant weight. FS was determined according to Eq. 1.

$$
F S(\%)=\frac{S_{(i)}-S_{(f)}}{S_{(i)}} \times 100
$$


$S_{(i)}=$ initial weight of film sample. $S_{(f)}=$ weight of film sample after drying.

\subsubsection{Film Moisture content (MC)}

141 MC of the film samples $(1.5 \times 4.0 \mathrm{~cm})$ was determined gravimetrically by measuring water

142 removed from the initial mass. The film samples were dried at $110^{\circ} \mathrm{C}$ for 24 hrs to attain a 143 constant weight. MC of the films was calculated according to Eq. 2.

$144 \quad F M C(\%)=\frac{M C_{(i)}-M C_{(f)}}{M C_{(i)}} \times 100$

$145 M C_{(i)}=$ initial weight of film sample. $M C_{(f)}=$ weight of film sample after drying

\subsubsection{Barrier Properties}

\subsubsection{Water vapour permeability (WVP)}

148 WVP was determined using gravimetric method, ASTM E96 procedure [22], as described in previous study [21]. Briefly, permeation cells (cup containing anhydrous $\mathrm{CaCl}_{2}$ granules with $0 \% \mathrm{RH})$ were sealed tightly by the sample film and placed under controlled $\mathrm{RH}$ conditions

151 ( $\mathrm{NaCl}$ saturated solution; $75 \% \mathrm{RH})$ at $25^{\circ} \mathrm{C}$. Water vapour transport was determined using the weight gain of the cell at a steady state of transfer. Changes in the weight of the cell were recorded and plotted as a function of time. The slope of each line was evaluated by linear regression $\left(\mathrm{R}^{2}>0.99\right)$, and the water vapour transmission was calculated through the slope of the straight line (g/s) divided by the test area $\left(\mathrm{m}^{2}\right)$. After the permeation tests, the film thickness was measured and WVP $\left(\mathrm{g} \mathrm{Pa}^{-1} \mathrm{~s}^{-1} \mathrm{~m}^{-1}\right)$ was calculated as:

$157 \quad \mathrm{WVP}=\frac{\Delta m}{A \Delta t} \frac{X}{\Delta P}$ 
$158 \Delta m / \Delta t=$ weight of moisture gain per unit time $\left(\mathrm{gs}^{-1}\right)$ and can be calculated by the slope of the graph. $\mathrm{A}=$ area of the exposed film surface $\left(\mathrm{m}^{2}\right), \mathrm{T}=$ thickness of the film $(\mathrm{mm}), \Delta P=$ represents

160 the water vapour pressure difference inside and outside of the film (Pa) [23].

161

162

163

164

165

166

167

168

169

170

171

172

173

174

175

176

177

\subsubsection{Optical properties}

\subsubsection{Film opacity}

FO measurements were performed according to previously described method [24] with some modifications. Rectangular film samples were placed in the cuvette loaded to the spectrophotometer (Cary 50 Bio UV-Visible spectrophotometer) and a blank cuvette was used as a reference. Absorbance was recorded at $560 \mathrm{~nm}$. Low value of opacity corresponds to high transparency. Opacity was calculated using Eq. 4.

$\mathrm{O}=\mathrm{AbS}_{560} / \mathrm{x}$

$\mathrm{O}=$ opacity of the film, Abs $560=$ Absorbance of the film at $560 \mathrm{~nm}, \mathrm{x}=$ thickness of the film in $\mathrm{mm}$.

\subsubsection{Colour measurement}

Film colour was determined by using Minolta colorimeter (Minolta CR-300 Japan). The colour profile was expressed as $\mathrm{L}=100$ (white) to $\mathrm{L}=0$ (black), $-\mathrm{a}=$ (greenness) to $+\mathrm{a}=$ (redness) and $-\mathrm{b}=$ (blueness) to $+\mathrm{b}=$ (yellowness). Total colour difference was calculated by the equation given below [25]. Ten readings of three different replicates were recorded and mean was calculated.

$\Delta \mathrm{E}=\left[(\Delta L)^{2}+(\Delta a)^{2}+\left(\Delta b^{2}\right)\right]^{1 / 2}$

Where, $\Delta L, \Delta a$ and $\Delta b$ are changes in the values of colour parameters. 
181 Tensile strength (TS) and elongation at break (EAB) were determined by Texture Analyzer

182 (LLOYD Instrument LTD, Fareham, UK) using previously developed method [21].

183 Preconditioned (60\% RH) films (15 x $40 \mathrm{~mm}$ ) were placed in the tensile grip with initial grip 184 distance $40 \mathrm{~mm}$ and $1 \mathrm{~mm} / \mathrm{s}$ crosshead speed. Eight samples from every formulation were 185 studied for the mechanical properties of the film. TS and EAB were expressed in MPa and $186 \mathrm{~N} / \mathrm{mm}$.

\subsubsection{Characterization of bio composite}

\subsubsection{Fourier transform infrared spectroscopy (FT-IR)}

FTIR spectra of starch-ı-car films were studied using infrared spectrometer (Thermo scientific

Nicolet iS10 FT-IR, USA). Spectral measurements were performed in the absorbance mode.

191 Each spectrum was recorded at the range of $400-4000 \mathrm{~cm}^{-1}$ with complete 32 scans at a 192 resolution of $4 \mathrm{~cm}^{-1}$ [2].

\subsubsection{2 $X$ - ray diffraction}

194 X-ray diffraction pattern of film compositions was obtained by using x-ray diffractometer 195 (PANanalytical, X’pert PRO Multi-purpose X-ray diffractometer, Almelo, Netherland) under 196 the following instrumental conditions: $40 \mathrm{~mA}, 40 \mathrm{kV}$, angle $2 \theta: 5.0^{\circ}$ and $59.9^{\circ}$, step size $=$ $1970.0130^{\circ}$, using $\mathrm{K} \alpha / \mathrm{K}$ cu radiations $(\lambda=1.54 / 1.39 \mathrm{~A})$. X-ray diffraction pattern for rice starch, 198 t-car and stearic acid was also analyzed to understand the crystalline behavior of the individual 199 compounds. 
Statistical analysis was performed using SPSS 23.0.0 statistical software for windows (SPSS

202

203

204

205

206

207

208

209

210

211

212

213

214

215

216

217

218

219

IBM, USA). One way ANOVA was used to analyse the data. The mean values were evaluated using Tukey's multiple comparison test and Duncan test with $\mathrm{p}<0.05$ denoted statistical significance.

\section{Results and discussion}

\subsection{Content of rice starch}

Amylose, proteins, ash, fat and moisture of starch was reported to affect the properties of starch [26]. Starch extracted from rice showed amylose $11.33 \%$, lipid $0.01 \%$, protein $0.71 \%$, moisture $11.64 \%$ and ash $4.9 \%$ respectively.

\subsection{Swelling power (SP) and Leached amylose (LA)}

SP is the indication of water absorption index of granules. Variations in the SP and LA are shown in the Fig. 1. SP of the RS-1-car blend increased with decrease in the starch concentration and varies between 9.0-17.75 g/g and significantly affected by $\mathrm{\imath}$-car concentration $(\mathrm{p}<0.05)$. High concentration of starch inhibited the swelling of starch granules due to increased amylose content. High absorption capacity of 1 -car and low amylose content provided the formulation F1 with high swelling power which decreases subsequently with increase in starch concentration from F1-F4. The reason could be explained on the basis inhibition effect of amylose on swelling capacity. Similar explanation is provided in the previous study based on composite starch combinations $[\mathbf{1 9}, \mathbf{2 6}]$. Furthermore, high absorption of -car with rice starch could minimizes the chances of phase separation which thus improving the permeability and mechanical properties of the film.

Simultaneously it is important to know the optimum time-temperature combination for effective gelatinization of starch in combination with other blending material. Starch reaches 
to its gelatinized temperature in between $80-90^{\circ} \mathrm{C}$ and similar range has been reported to be suitable for -car to form a gelling mixture [19]. Findings of present study revealed that time has a significant impact $(\mathrm{p}<0.05)$ on the gelatinization mechanism as it reflects the amount of leached amylose (apparent amylose). At low time-temperature combination $\left(5 \mathrm{~min} / 90^{\circ} \mathrm{C}\right)$ the amount of leached amylose was low (0.7-4.5 g/g) however it increased significantly when formulations (F1-F4) were heated continuously for 10 minutes. It is important to note that further increase in heating time reduces the amount of leached amylose content. Reason can be explained on the basis of partial gelatinization in which leached out amylose prevent the further amylose from leaching out. Thus the availability of free amylose reduces for interaction with the carrageenan and affects the mechanical and barrier attributes of film [27].

\subsection{FTIR spectra}

Infrared spectroscopy is a powerful tool widely used for the characterization of polysaccharides to study the molecular interactions characterised by the shifting of absorption bands [28]. Influence of different ingredient ratios on shifting of IR characteristic bands is shown in Fig. 2. Changes in the absorption bands stretching indicates the possible structural interactions between the partaking components in the coating matrix [29]. FT-IR spectra of composite film showed some common characteristics absorption bands at different wave numbers. $2851 \mathrm{~cm}^{-1}$ $3050 \mathrm{~cm}^{-1}$ represents the C-H stretching vibrations. $2912 \mathrm{~cm}^{-1}$ corresponds to $-\mathrm{OH}$ functional group formed due to the vibrational stretching associated with free inter and intra molecular bonds in -OH groups. The assignment of these bands are in line with previous reported results with konjac-glucomannan/curdlan [30], k-carrageenan and locust bean [31], carboxymethylgellan and pullulan [2]. It is also important to mention about smaller bands at the wavenumber ranges from $700-1000 \mathrm{~cm}^{-1}$ representing the fingerprinting region denoting the characteristic signatures of each polysaccharide. Spectral region between $800-950 \mathrm{~cm}^{-1}$ corresponds to C-O$\mathrm{SO}_{3}$ on $\mathrm{C}_{2}$ of 3,6-anhydrogalactosen, $\mathrm{C}-\mathrm{O}-\mathrm{SO}_{3}$ on $\mathrm{C}_{4}$ of galactose, $\mathrm{C}-\mathrm{O}-\mathrm{SO}_{3}$ on $\mathrm{C}_{2}$ of 3,6- 
anhydrogalactose, C-O of 3,6-anhydrogalactose respectively [32]. Similar bands were observed in the RS-1-car spectra at wavenumbers $740 \mathrm{~cm}^{-1}$ (3, 6-anhydro-D-galactose), $800 \mathrm{~cm}^{-}$ ${ }^{1}$ representing anomeric configuration ( $\alpha$-D-galactopyranose unit). The wavenumbers, $852 \mathrm{~cm}^{-}$ sulphate) attributed to the presence of ester sulphate groups which are the characteristics of sulphated polysaccharide compounds. Film formulation F1-F4 showed bands stretching at $1200-1300 \mathrm{~cm}^{-1}$, shifting of bands in this region is due to interactions between the charged functional groups between the polysaccharides. The additional major peak at $1652 \mathrm{~cm}^{-1}$ observed in the infrared spectra of RS-ı-car film could be assigned for water. Formation of inter- molecular interactions in RS-ı-car film influences the interactions and miscibility between these two polysaccharides can be observed in the stretched regions. Finding of this work are in line with previous work based on the characterization of k-car-LBG film [31, 33].

\section{$3.4 X$ - ray diffraction}

A semicrystalline pattern of blended film compared with pure ingredients is shown in the Fig.

3. XRD curve shows broad and sharp peaks comprising amorphous and crystalline region respectively. Amorphous-crystalline structural transitions induced as a result of molecular interactions between polysaccharides are responsible for their varying functional properties and favours the amorphous structure [31]. A typical A-type polymorphic form was observed for pure rice starch with unresolved peaks $\left(2 \theta=17^{\circ} \& 18^{\circ}\right)$ and separate peaks $\left(2 \theta=15^{\circ} \& 23^{\circ}\right)$. The $\mathrm{XRD}$ pattern is similar to the previously reported results conducted on native and modified rice starch [34]. Pattern showed some small peaks in the region $2 \theta=7^{\circ}-15^{\circ}$ and two broad peaks at $2 \theta=22^{\circ} \& 24^{\circ}$ probably due to the presence of stearic acid crystallites. From the XRD profile

272 it is clear that miscibility of blended formulation (F1-F4) affected by the varying concentration 273 of ingredients. As it could be seen from the XRD profile that intensity of crystallite peaks 
decreases with the increase in $\mathrm{t}$-car concentration from F4 (0.50\%) to F1 (2\%), indicating that crystallinity of RS-1-car-stearic acid films were strongly influenced by the presence of carrageenan. The interaction mechanism between starch-carrageenan may be correlated to the adsorption of carrageenan molecules on starch surface which destroy the crystalline domain of the biopolymers [35]. The possible interactions between these moieties which has led to the broadening of peak area, is a good indicator of miscibility between the partaking ingredients.

Furthermore, it is worth noting that sharp peaks at $2 \theta \sim 22^{\circ} \& 24^{\circ}$ varied with stearic acid content and higher for F4 formulation (0.9\%) than F1 formulation (0.3\%). The possible reason could be due to the agglomeration of stearic acid content over the film surface after drying signifies that there exists some phase separation between two biopolymers. Similar behaviour regarding the accumulation of stearic acid crystals (lipid agglomeration) on the cassava starch based film was also observed in previously reported by Chiumarelli and Hubinger [6].

In conclusion, results of XRD study explained the compatibility of starch and carrageenan in combination with other components however, accurate concentrations of stearic acid is necessary to improve the barrier properties of film while maintaining the other important attributes.

\subsection{Thickness (FT)}

FT greatly influences the WVP and transparency of the film. Precise and accurate measurement of this parameter is really important to avoid the effect to barrier properties. Thickness of rice starch-1-car films varied between 0.084 and $0.114 \mathrm{~mm}$ respectively. FT corresponding to different formulations is summarized in Fig. 4a. Formulation F1, comprising 2\% rice starch and $2 \%$ t-car with $0.3 \%$ stearic acid gives a film of minimum thickness. Increase in starch concentration from the formulation F1-F4 made it possible to have a significant impact on the 
297 film thickness $(\mathrm{p}<0.05)$. Similar results were reported in the previous study where starch concentration had a profound effect on the thickness of biopolymer film [36].

Interactions between the hydrocolloids affect the film affinity for water. Table 2 describes the variations in the MC of composed film. Polysaccharides-lipid ratio significantly affect $(\mathrm{p}<0.05)$ the moisture content of film. To the formulation F1, higher concentration of galactans (2\%) minimizes the moisture content of edible film (8.48\%). MC was maximum at 3\% starch, $1 \%$ tcar and $0.7 \%$ stearic acid. Results of this study are consistent with the previously reported data where increased concentrations of $\mathbf{\imath}$-car lower the moisture content of the edible film [31]. The most probable reason for this behaviour could be due to the lack of interactions sites, possibly because of entrapment of starch molecules in the -car double helices structure. Another possible reason for this trend could be due to the crosslinking interactions between the polymers. The availability of free $\mathrm{OH}$ groups diminishes as a result of anionic sulphate and starch -OH group interactions at higher galactan concentration. Moreover, as the availability of $\mathrm{OH}$ group increases polysaccharide - water interaction dominated accordingly. Similar explanation was provided in the previous study based on galactans [37]. It is worth noting that the further increase in stearic acid (0.7-0.9\%) and starch concentration (3-4\%) resulted to the declines in film moisture content $(\mathrm{p}<0.05)$. This could be due to increased fatty acid content which increased the hydrophobicity of the film matrix which affect the moisture content of film.

\subsection{Film solubility}

318 Solubility ranged from $43.35 \%$ to $63.22 \%$ which are good values for fruit applications (Fig. 5b). Solubility values were affected significantly $(\mathrm{p}<0.05)$ with the increase in 1 -car concentration. Formulation F1 (2\% rice starch: $2 \%$ t-car: $0.3 \%$ stearic acid) showed the 
maximum solubility value (63.22\%) which decreases gradually from formulation F1 to F4. 1-

322

323

324 car undergoes structural modifications (coil to double helix) when combines with excess water [38]. Moreover, these structural transitions were largely dependent on the content of ester sulphate, type of carrageenan, temperature and concentration [39]. Solubility was lowest $(\mathrm{p}<0.05)$ at formulation F4 consisting of $0.5 \%$ t-car with high starch $(4 \%)$ and fatty acids (0.9\%) concentrations. Most probable reason associated with this trend could be due to increase in the lipid content of film suspension solution from formulation F1-F4. The findings of this study are in line with the previous study where increased concentration of lipids affected the solubility of edible film [40].

\subsection{Water vapour permeability (WVP)}

Minimum WVP of edible films describes the better barrier properties. Polysaccharide based edible coating including -car has low permeability values [41]. Film formulation F1, containing $2 \%$ rice starch and $2 \%$-car with $0.3 \%$ stearic acid showed the minimum WVP (3.55 $\left.\mathrm{x} 10^{-11} \mathrm{gs}^{-1} \mathrm{~m}^{-1} \mathrm{~Pa}^{-1}\right)$ values $(\mathrm{p}<0.05)$ as compared to formulation $\mathrm{F} 2\left(4.22 \times 10^{-11} \mathrm{gs}^{-1} \mathrm{~m}^{-1} \mathrm{~Pa}^{-1}\right)$ and F3 (4.57 x 10 $\left.{ }^{-11} \mathrm{gs}^{-1} \mathrm{~m}^{-1} \mathrm{~Pa}^{-1}\right)$. Formulation F1and F4 presented no significant statistical difference ( $>0.05$ ) showing better WVP values, however it was found to be statistically different $(\mathrm{p}<0.05)$ with F1 \& F3 formulations (Fig.4b). Similar results were reported in the previous study where WVP value substantially decreased as the concentration of $\mathrm{l}$-car was increased from 0 to $100 \%$ [31]. The differences in the permeability with in the formulations may be due to the interactions between the film components. -car acts as a protector for starch granules [42]. Double helical structure of carrageenan acts as a protector for the starch molecule and trap it in the coiled structure (graphical abstract). Strong networking interactions with rice starch gives a compact crystalline structure which strengthens the polymeric chain integrity of film. Interactions study between starch-ı-car complexes using confocal scanning laser microscopy provided the similar explanation for such type of behaviour of these 
polysaccharides [35] however, comprehensive detail future study is required to understand the mechanism thoroughly.

It is also worth mentioning that in spite of lowering the level of 1 -car (0.5\%), WVP unexpectedly decreased at F4 with higher level of lipid content. Similar behaviour was observed in the cassava starch based edible films using lipid as a hydrophobic component where the rate of permeate transfer was higher at lower concentration of oleic acid and decreased sequentially. [6]. This could be due to the hydrophilic-hydrophobic ratio in the film structure. Fatty acid in film matrix imparts the hydrophobic character resulting in to morphological alterations in the film structure $[43,44]$. At low fatty acid concentration water molecules permeate the hydrophilic matrix through a straight path however permeation becomes difficult at high fatty acid concentration with dominated hydrophobicity of film. Moreover, Low rate of permeate migration at higher starch concentration could also be explained on the basis of thickness of film. Thickness of film increases $(p<0.05)$ with the increase in starch concentration (2-4\%) and was maximum at F4 (0.114 mm). Thickness of the film matrix is straightly related to starch concentration which describes the increasing solid density of film matrix and promoted the resistance to the water vapour permeability [45].

\subsection{Opacity and colour}

Opacity of film ranged from 0.5 to $1.0 \%$ (Table 2). Lowest opacity value corresponds to high transparency which is prerequisite for the fruit packaging. Minimum and maximum opacity values were recorded for F1 and F4 respectively $(\mathrm{p}<0.05)$. 1 -car also forms a transparent gel solution on heating and gives less opacity than starch solution [43]. The RS-1-car mixture was clear for the formulation F1 and becomes turbid with the increase in starch (2-4\%) and fatty acid (0.3-0.9\%) concentration. Results are in line with the previous study where fatty acids provided the less transparency to the resulting film [46]. In term of colour there exists no 
statistical differences in the $\Delta \mathrm{E}$ value of $\mathrm{F} 1, \mathrm{~F} 2$ and $\mathrm{F} 4$ formulations however $\Delta \mathrm{E}$ value was slightly higher in case of F3 which may be probably due to higher MC (Table 2). More MC might affect the reflection pattern of light passing through the film surface thus increasing the $\mathrm{b}^{*}$ value (yellow-blue shade). Similar behaviour was reported in the previous study where presence of moisture affected the colour properties of film [31].

\subsection{Mechanical properties-TS and EAB}

Tensile strength describes the maximum stress developed on the film material. TS and EAB values of different blends (F1-F4) of starch-1-car film are presented in Fig. 6 (a, b) with significantly different values $(\mathrm{p}<0.05)$. Formulation F1 ( $2 \%$-car) presented the high tensile strength $\left(116.5 \mathrm{~N} / \mathrm{m}^{2}\right)$ which has contributed to the formation of stronger structure. Mechanical properties gradually decreased with the lowering in galactan concentration $(0.5 \%)$ and was minimum $\left(31.6 \mathrm{~N} / \mathrm{m}^{2}\right)$ at $\mathrm{F} 4$ with $0.5 \% \mathrm{t}$-car and $0.9 \%$ stearic acid. Finding of this study are similar to previous results where mechanical properties of the film improved with the escalation in $\mathbf{l - c a r}$ concentration [19] and decreased with the increase in fatty acid concentration [47]. It is interesting to note that EAB for F1 was surprisingly higher (45.60 mm) than other formulations and follow the same trend as TS $(\mathrm{p}<0.05)$. EAB for formulations F1-F4 ranged from (15.7 to $45.60 \mathrm{~mm})$. Formulation F4 showed the lowest value of TS and EAB $(p<0.05)$. This trend finds the possible explanation on the basis of interactions and compatibility of rice starch with -car. The -car helices associations in the film matrix presented a more compact matrix when sample reaches to its gelation temperature and forms 3D structure as a result of chain pairing with the adjacent -car and rice starch. Similar explanation is provided in the previous study about the interaction of these biopolymers [39].

\section{Conclusion}


RS-ı-car blends provided the film with different varying properties. Coating formulation F1 composed of $2 \%$ rice starch and $2 \%$ t-car concentration provided the film with minimum thickness, better solubility, WVP and enhanced mechanical properties. However selection and concentration of fatty acid is important to control the harm to film properties. FT-IR, XRD study reveals that there exists compatibility and miscibility between the biopolymers and can be a suitable alternative for fruits coatings applications with accurate addition of hydrophobic component. Results of this study indicates that increased concentration of carrageenan with low stearic acid is effective in improving the physical, mechanical and barrier properties of film. However further study involving interactions between starch and carrageenan along with different fatty acids will be of great interest.

\section{Acknowledgement}

This work was supported by the University of Newcastle, Australian Research Council (ARC) Training Centre for Food and Beverage Supply Chain and Optimisation (IC140100032). NSW Department of Primary Industries is a partner organisation in the Training Centre.

\section{References}

[1] Z. Zhou, K. Robards, S. Helliwell, C. Blanchard, Effect of the addition of fatty acids on rice starch properties, Food Research International 40(2) (2007) 209-214.

[2] G. Zhu, L. Sheng, Q. Tong, Preparation and characterization of carboxymethyl-gellan and pullulan blend films, Food Hydrocolloids 35 (2014) 341-347.

[3] S.Y. Park, B.I. Lee, S.T. Jung, H.J. Park, Biopolymer composite films based on k-carrageenan and chitosan, Materials Research Bulletin 36(3-4) (2001) 511-519.

[4] M.E. Embuscado, K.C. Huber, Edible films and coatings for food applications, Springer2009. [5] D. Muscat, R. Adhikari, S. McKnight, Q. Guo, B. Adhikari, The physicochemical characteristics and hydrophobicity of high amylose starch-glycerol films in the presence of three natural waxes, Journal of Food Engineering 119(2) (2013) 205-219.

[6] M. Chiumarelli, M.D. Hubinger, Evaluation of edible films and coatings formulated with cassava starch, glycerol, carnauba wax and stearic acid, Food Hydrocolloids 38 (2014) 20-27.

[7] J. Liang, Q. Xia, S. Wang, J. Li, Q. Huang, R.D. Ludescher, Influence of glycerol on the molecular mobility, oxygen permeability and microstructure of amorphous zein films, Food Hydrocolloids 44 (2015) 94-100.

[8] N. Cao, X. Yang, Y. Fu, Effects of various plasticizers on mechanical and water vapor barrier properties of gelatin films, Food Hydrocolloids 23(3) (2009) 729-735. 
[9] W. Randazzo, A. Jiménez-Belenguer, L. Settanni, A. Perdones, M. Moschetti, E. Palazzolo, V. Guarrasi, M. Vargas, M.A. Germanà, G. Moschetti, Antilisterial effect of citrus essential oils and their performance in edible film formulations, Food Control 59 (2016) 750-758. [10] M. Rodríguez, J. Osés, K. Ziani, J.I. Maté, Combined effect of plasticizers and surfactants on the physical properties of starch based edible films, Food Research International 39(8) (2006) 840-846. starch source and concentration, plasticizer, surfactant's hydrophobic tail and mechanical treatment, Food Hydrocolloids 49 (2015) 89-94.

[12] C. Soukoulis, P. Singh, W. Macnaughtan, C. Parmenter, I.D. Fisk, Compositional and physicochemical factors governing the viability of Lactobacillus rhamnosus $\mathrm{GG}$ embedded in starchprotein based edible films, Food Hydrocolloids 52 (2016) 876-887.

[13] D.K. Das, H. Dutta, C.L. Mahanta, Development of a rice starch-based coating with antioxidant and microbe-barrier properties and study of its effect on tomatoes stored at room temperature, LWT - Food Science and Technology 50(1) (2013) 272-278.

[14] S. Aila-Suárez, H.M. Palma-Rodríguez, A.I. Rodríguez-Hernández, J.P. Hernández-Uribe, L.A. Bello-Pérez, A. Vargas-Torres, Characterization of films made with chayote tuber and potato starches blending with cellulose nanoparticles, Carbohydrate Polymers 98(1) (2013) 102-107.

[15] F.M. Fakhoury, S. Maria Martelli, L. Canhadas Bertan, F. Yamashita, L.H. Innocentini Mei, F.P. Collares Queiroz, Edible films made from blends of manioc starch and gelatin - Influence of different types of plasticizer and different levels of macromolecules on their properties, LWT - Food Science and Technology 49(1) (2012) 149-154.

[16] A.A. Adebowale, O.O. Olatunde, M.O. Adegunwa, W.B. Asiru, L.O. Sanni, Mechanical and Sensorial Characteristics of Cassava and Yam Composite Starch Films, Journal of Food Processing and Preservation 38(4) (2014) 1994-1998.

[17] C. Fabian, A. Ayucitra, S. Ismadji, Y.-H. Ju, Isolation and characterization of starch from defatted rice bran, Journal of the Taiwan Institute of Chemical Engineers 42(1) (2011) 86-91.

[18] L. Chen, Q. Tong, F. Ren, G. Zhu, Pasting and rheological properties of rice starch as affected by pullulan, Int. J. Biol. Macromol. 66 (2014) 325-31.

[19] J.-H. Lin, C.-W. Liang, Y.-H. Chang, Effect of starch source on gel properties of kappacarrageenan-starch dispersions, Food Hydrocolloids 60 (2016) 509-515.

[20] J. Chrastil, Improved colorimetric determination of amylose in starches or flours, Carbohydr. Res. 159(1) (1987) 154-158.

[21] B. Saberi, Q. Vuong, S. Chockchaisawasdee, J. Golding, C. Scarlett, C. Stathopoulos, Water sorption isotherm of pea starch edible films and prediction models, Foods 5(1) (2016) 1.

[22] A. E96-95, Standard Test Methods for Water Vapor Transmission of Material, American Society for Testing and Materials, Philadelphia, PA, 1995.

[23] B. Saberi, Q. Vuong, S. Chockchaisawasdee, J. Golding, C. Scarlett, C. Stathopoulos, Mechanical and physical properties of pea starch edible films in the presence of glycerol, J. Food Process.

Preserv. (2015) In Press.

[24] J.G. Gómez-Estaca, B. Montero, P. Gómez-Guillén, M. C., Incorporation of antioxidant borage extract into edible films based on sole skin gelatin or a commercial fish gelatin, J. Food Eng. 92(1) (2009) 78-85.

[25] A. Gennadios, C.L. Weller, M.A. Hanna, G.W. Froning, Mechanical and Barrier Properties of Egg Albumen Films, J. Food Sci. 61(3) (1996) 585-589.

[26] C.E. Chinma, C.C. Ariahu, J.O. Abu, Chemical composition, functional and pasting properties of cassava starch and soy protein concentrate blends, Journal of Food Science and Technology 50(6) (2013) 1179-1185.

[27] K. Tsutsui, K. Katsuta, T. Matoba, M. Takemasa, K. Nishinari, Effect of Annealing Temperature on Gelatinization of Rice Starch Suspension As Studied by Rheological and Thermal Measurements, J. Agric. Food Chem. 53(23) (2005) 9056-9063. 
[28] A. Synytsya, M. Novak, Structural analysis of glucans, Annals of Translational Medicine 2(2) (2014) 17.

[29] R.K. Wanchoo, P.K. Sharma, Viscometric study on the compatibility of some water-soluble polymer-polymer mixtures, European Polymer Journal 39(7) (2003) 1481-1490.

[30] C. Wu, S. Peng, C. Wen, X. Wang, L. Fan, R. Deng, J. Pang, Structural characterization and properties of konjac glucomannan/curdlan blend films, Carbohydrate Polymers 89(2) (2012) 497503.

[31] J.T. Martins, M.A. Cerqueira, A.I. Bourbon, A.C. Pinheiro, B.W.S. Souza, A.A. Vicente, Synergistic effects between $\mathrm{k}$-carrageenan and locust bean gum on physicochemical properties of edible films made thereof, Food Hydrocolloids 29(2) (2012) 280-289.

[32] L. Pereira, A.M. Amado, A.T. Critchley, F. van de Velde, P.J.A. Ribeiro-Claro, Identification of selected seaweed polysaccharides (phycocolloids) by vibrational spectroscopy (FTIR-ATR and FTRaman), Food Hydrocolloids 23(7) (2009) 1903-1909.

[33] M.A. Cerqueira, A.I. Bourbon, A.C. Pinheiro, J.T. Martins, B.W.S. Souza, J.A. Teixeira, A.A. Vicente, Galactomannans use in the development of edible films/coatings for food applications, Trends in Food Science \& Technology 22(12) (2011) 662-671.

[34] L. Bian, H.-J. Chung, Molecular structure and physicochemical properties of starch isolated from hydrothermally treated brown rice flour, Food Hydrocolloids 60 (2016) 345-352.

[35] D. Huc, A. Matignon, P. Barey, M. Desprairies, S. Mauduit, J.M. Sieffermann, C. Michon, Interactions between modified starch and carrageenan during pasting, Food Hydrocolloids 36 (2014) 355-361.

[36] E. Basiak, F. Debeaufort, A. Lenart, Effect of oil lamination between plasticized starch layers on film properties, Food Chem 195 (2016) 56-63.

[37] T. Watanabe, A. Ohtsuka, N. Murase, P. Barth, K. Gersonde, NMR studies on water and polymer diffusion in dextran gels. Influence of potassium ions on microstructure formation and gelation mechanism, Magn. Reson. Med. 35(5) (1996) 697-705.

[38] E. Tavassoli-Kafrani, H. Shekarchizadeh, M. Masoudpour-Behabadi, Development of edible films and coatings from alginates and carrageenans, Carbohydrate Polymers 137 (2016) 360-374.

[39] M. lijima, T. Hatakeyama, M. Takahashi, H. Hatakeyama, Effect of thermal history on kappacarrageenan hydrogelation by differential scanning calorimetry, Thermochimica Acta 452(1) (2007) 53-58.

[40] S.J. Kim, Z. Ustunol, Solubility and moisture sorption isotherms of whey-protein-based edible films as influenced by lipid and plasticizer incorporation, Journal of agricultural and food chemistry 49(9) (2001) 4388-91.

[41] A.E. Pavlath, W. Orts, Edible Films and Coatings: Why, What, and How?, in: C.K. Huber, E.M. Embuscado (Eds.), Edible Films and Coatings for Food Applications, Springer New York, New York, NY, 2009, pp. 1-23.

[42] P.C.S.F. Tischer, M.D. Noseda, R.A. de Freitas, M.R. Sierakowski, M.E.R. Duarte, Effects of iotacarrageenan on the rheological properties of starches, Carbohydr Polym 65(1) (2006) 49-57.

[43] T. Karbowiak, H. Hervet, L. Leger, D. Champion, F. Debeaufort, A. Voilley, Effect of plasticizers (water and glycerol) on the diffusion of a small molecule in iota-carrageenan biopolymer films for edible coating application, Biomacromolecules 7(6) (2006) 2011-9.

[44] M.A. García, M.N. Martino, N.E. Zaritzky, Lipid Addition to Improve Barrier Properties of Edible Starch-based Films and Coatings, Journal of food science 65(6) (2000) 941-944.

[45] R. Villalobos-Carvajal, P. Hernández-Muñoz, A. Albors, A. Chiralt, Barrier and optical properties of edible hydroxypropyl methylcellulose coatings containing surfactants applied to fresh cut carrot slices, Food Hydrocolloids 23(2) (2009) 526-535.

[46] F.M. Fakhouri, L.C.B. Fontes, L.H. Innocentini-Mei, F.P. Collares-Queiroz, Effect of Fatty Acid Addition on the Properties of Biopolymer Films Based on Lipophilic Maize Starch and Gelatin, Starch - Stärke 61(9) (2009) 528-536. 
525 [47] N. Gontard, C. Duchez, J.-L. Cuq, S. Guilbert, Edible composite films of wheat gluten and lipids: 526 water vapour permeability and other physical properties, International Journal of Food Science \& 527 Technology 29(1) (1994) 39-50.

528

529

530

531

532 


\section{Graphical Abstract}
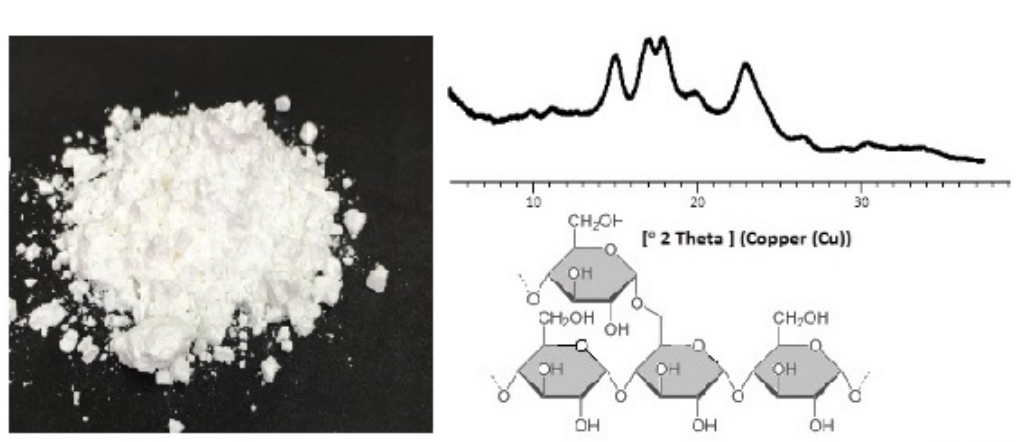

Rice starch

Blending of Rice starch 1-carrageenan + Stearic acid

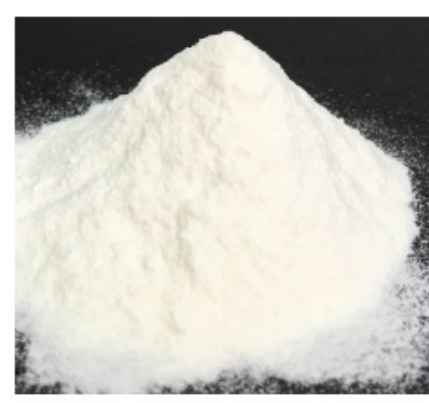

l-carrageenan

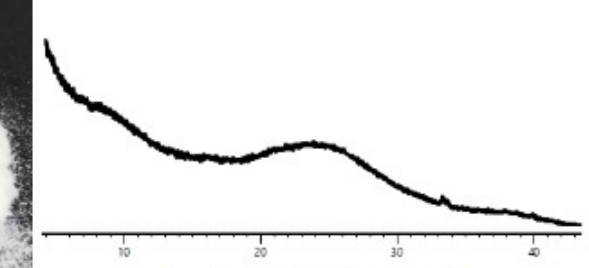

Position [ 2 Theta ] (Copper (Cu))
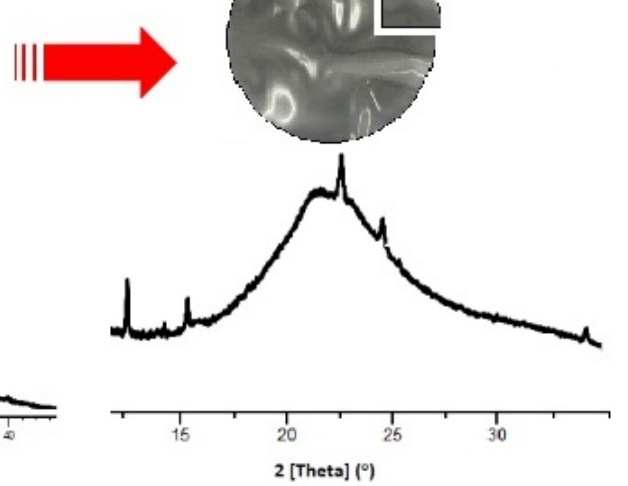

ति

RS---car complex

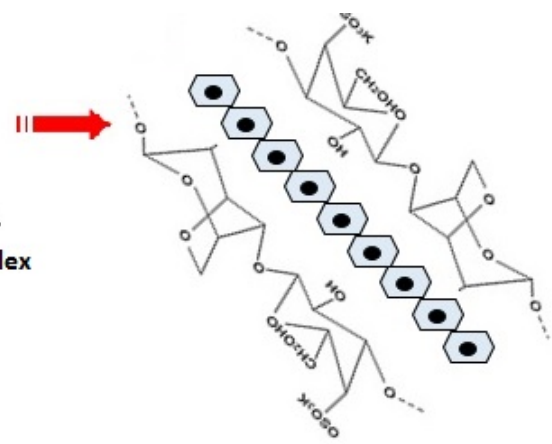

\begin{tabular}{ll}
\hline \hline & Thickness \\
WVP \\
Moisture content \\
Opacity
\end{tabular}

Tensile strength

Elongation at break Solubility

Graphical representation of mechanism of interaction between rice starch-carrageenan and stearic acid. 


\section{Captions}

Fig. 1. Swelling power and leached amylose content of RS-ı-car formulations (F1-F4) at $90^{\circ} \mathrm{C}$.

Fig. 2. FT-IR spectra of rice starch-1-car film samples (F1-F4) in the region $400-3050 \mathrm{~cm}^{-1}$.

Fig. 3. X-ray diffraction pattern of film matrix. (a) t-carrageenan, (b) stearic acid, (c) rice starch, (d) RS-ı-car-stearic acid blended film formulation F1-F4. Where F1=RS/l-car/SA (2\%, 2\%,0.3\%), F2=(2.5\%,1.5\%,0.5\%), F3=(3\%,1\%,0.5\%), F4=(4\%,0.5\%,0.7\%).

Fig. 4. Thickness (a), WVP (b) of rice starch---car film blended with fatty acid, glycerol and surfactant. For (b) Values are multiplied by $1 \times 10^{-11}$. Values denotes the means of replicates \pm Standard error. ${ }^{\mathrm{a}-\mathrm{c}}$ represents the difference between mean values.

Fig. 5. Opacity (a), Solubility (b) of rice starch-1-car film blended with fatty acid, glycerol and surfactant. Values denotes the means of replicates \pm Standard error. ${ }^{\mathrm{a}-\mathrm{c}}$ represents the difference between mean values.

Fig. 6. Change in (a) Tensile strength (TS), (b) Elongation at break (EAB) of rice starch-ı-car film blended with fatty acid, glycerol and surfactant. Values denotes the means of replicates \pm Standard error. ${ }^{\mathrm{a}-\mathrm{c}}$ represents the difference between mean values. The values with the same letter are not significantly different according to Duncan's multiple range test $(\mathrm{p}>0.05)$.

Graphical abstract: Graphical representation of mechanism of interaction between rice starch-carrageenan and stearic acid. 
Journal Name: International Journal of Biological Macromolecules Author Name: Rahul Thakur

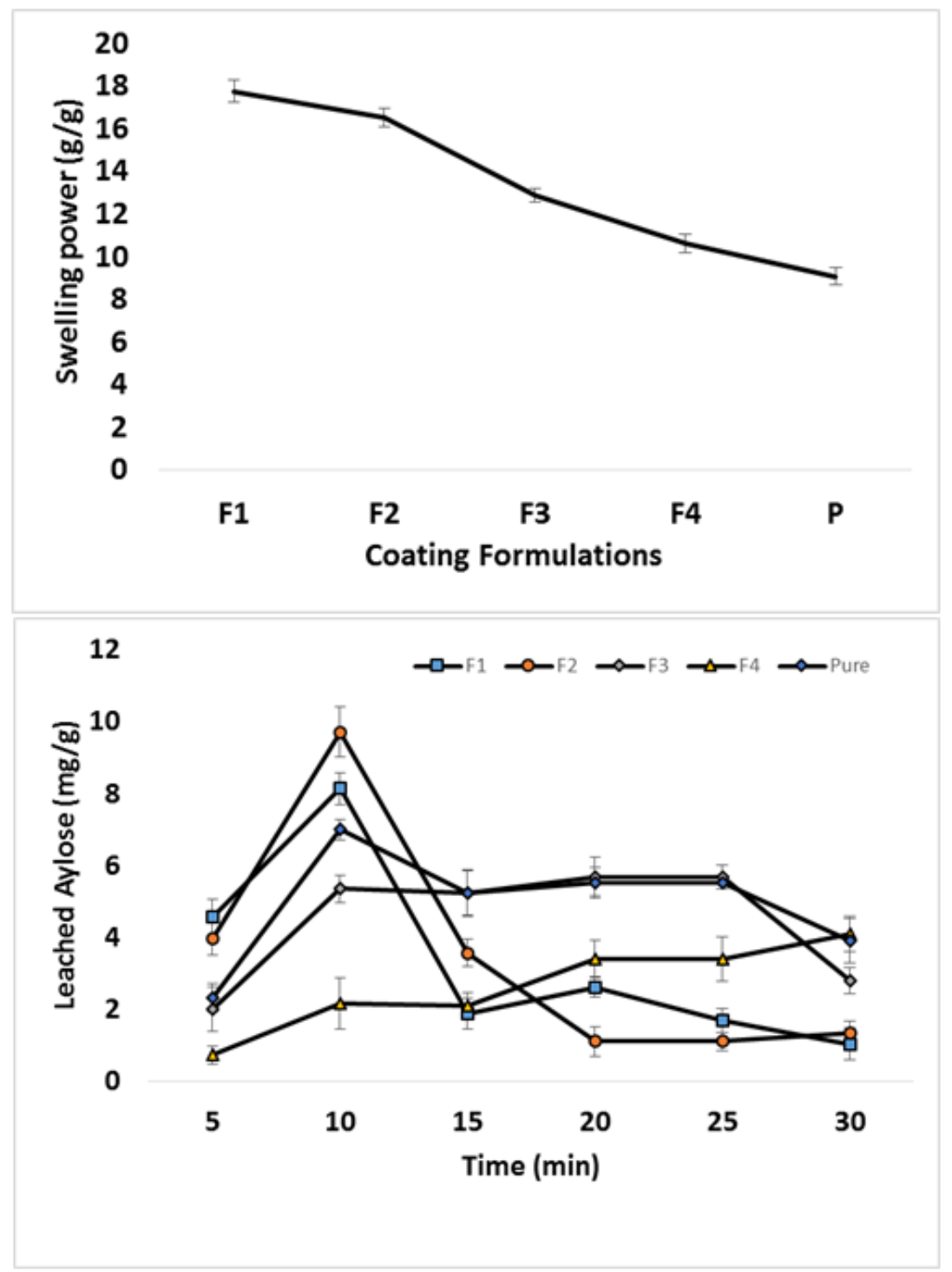

Fig. 1 
Journal Name: International Journal of Biological Macromolecules

Author Name: Rahul Thakur

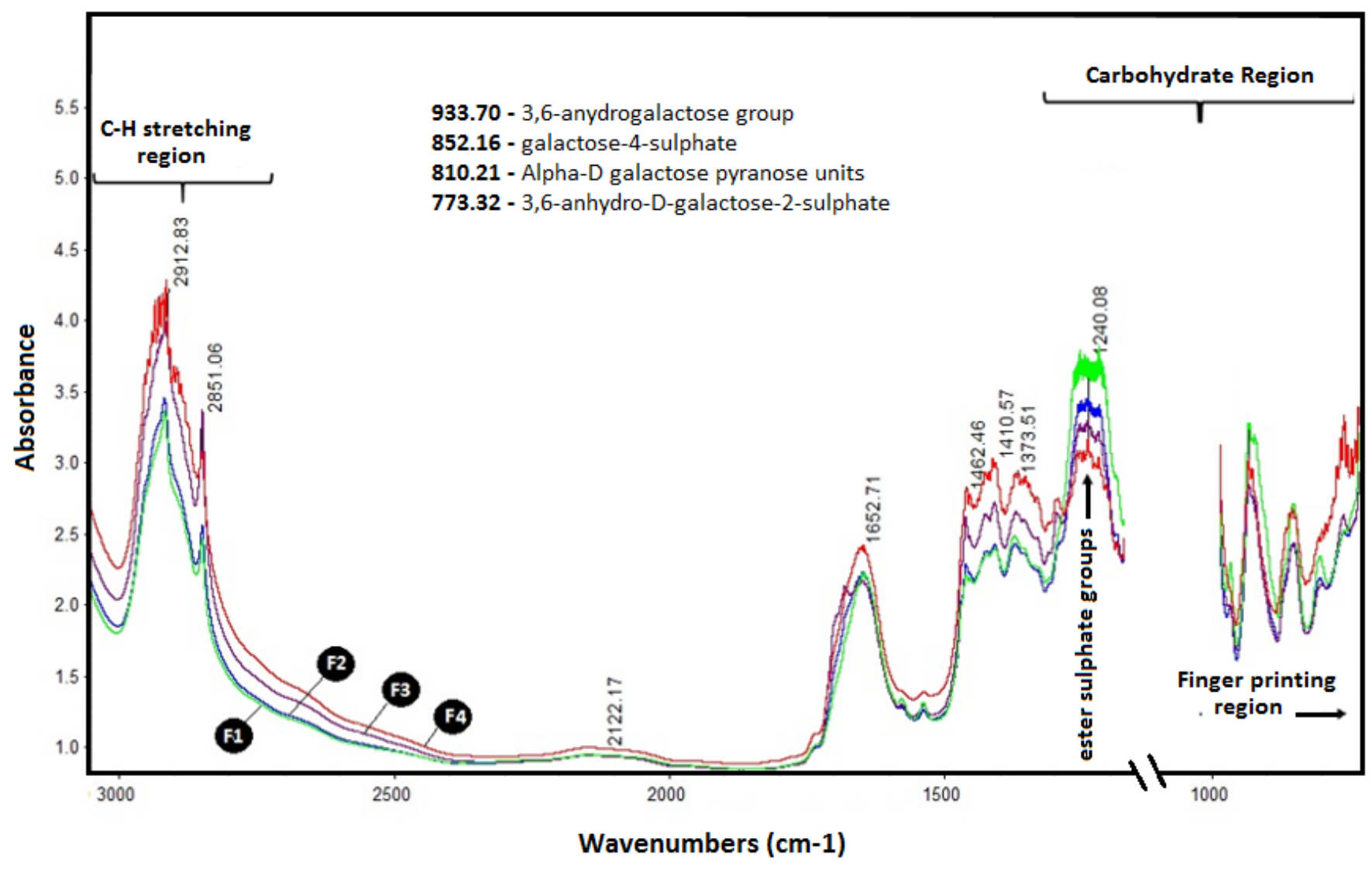

Fig. 2 
Journal Name: International Journal of Biological Macromolecules Author Name: Rahul Thakur
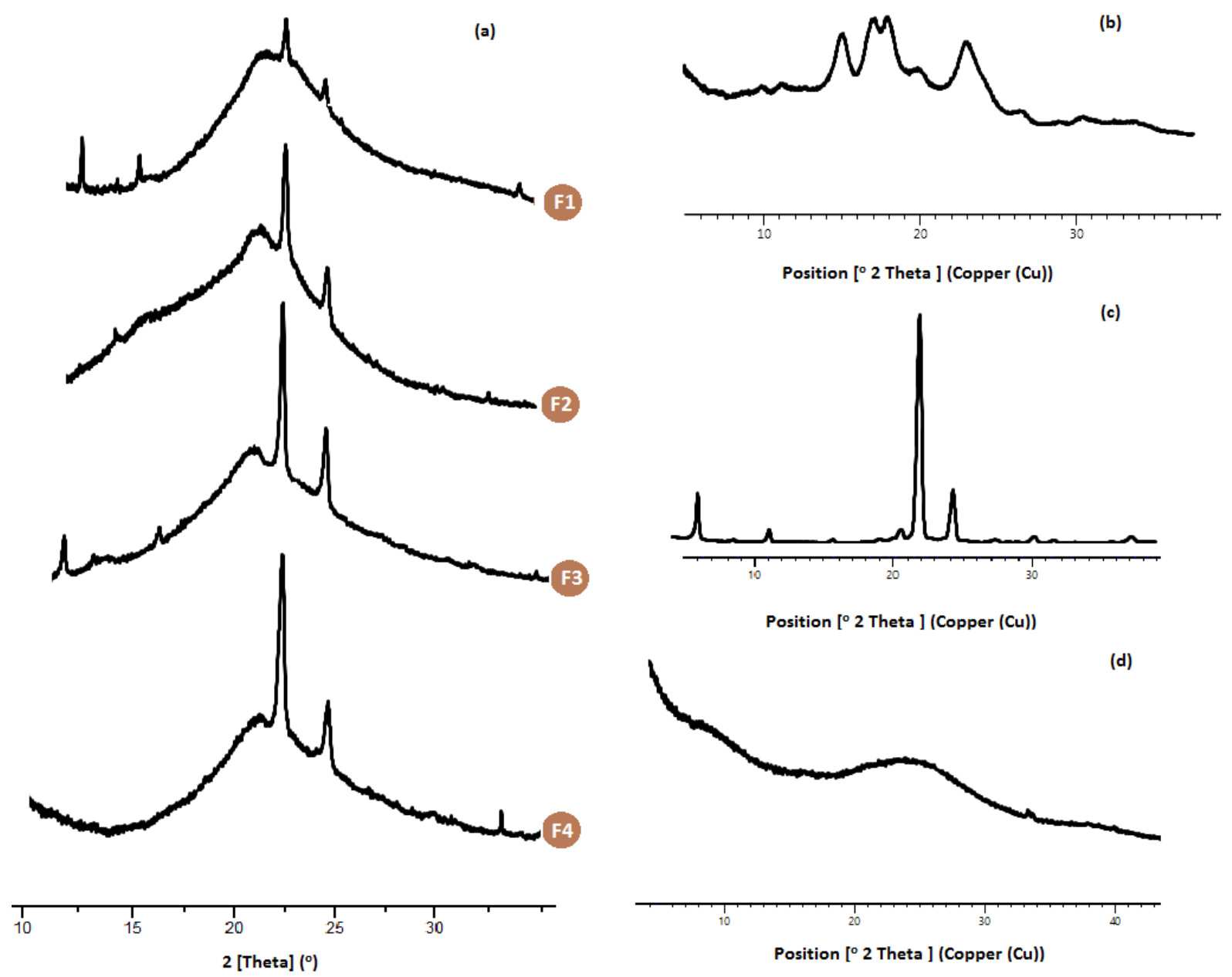

Fig. 3 
Journal Name: International Journal of Biological Macromolecules Author Name: Rahul Thakur

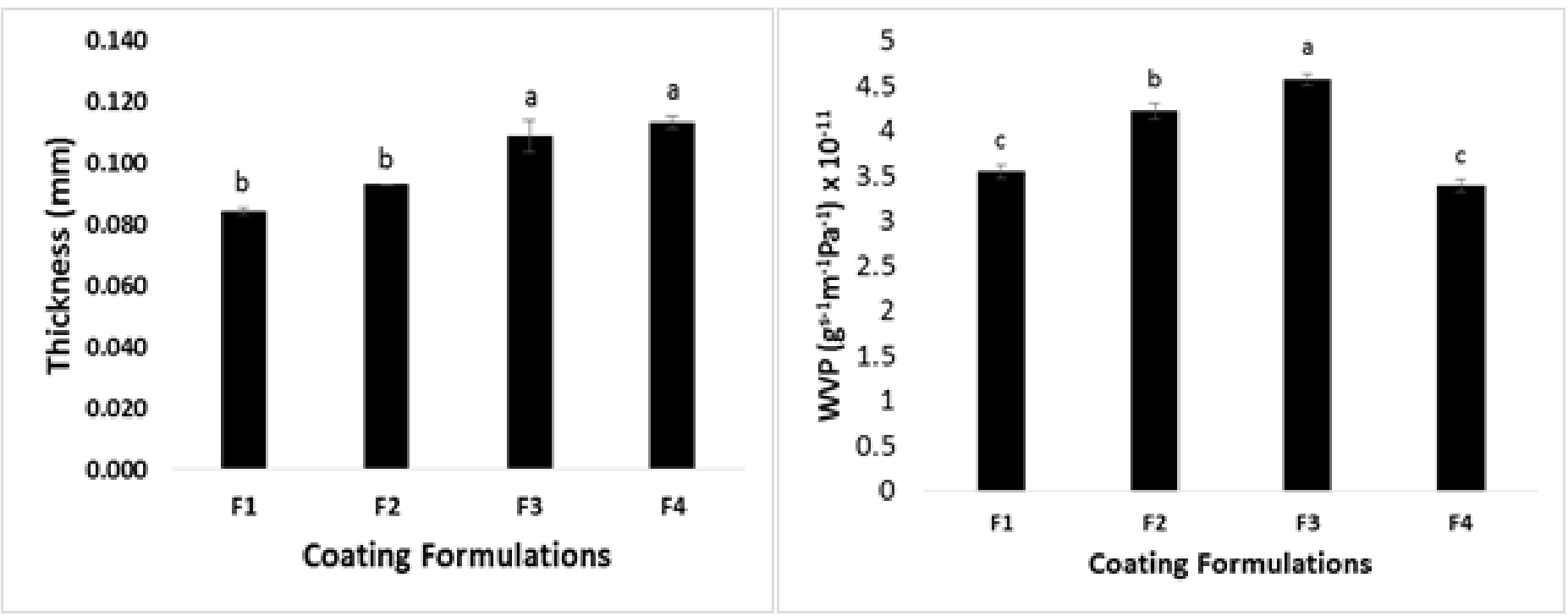

(a)

(b)

Fig. 4 (a, b) 
Journal Name: International Journal of Biological Macromolecules

Author Name: Rahul Thakur

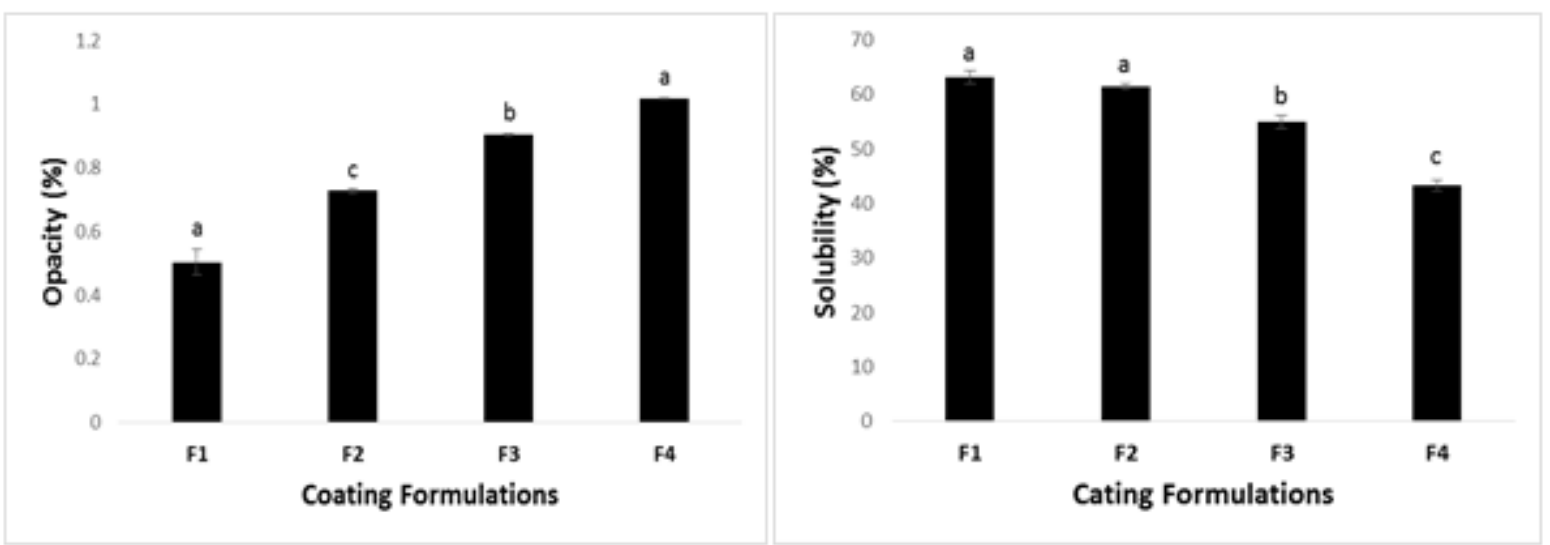

(a)

(b)

Fig. 5 (a, b) 
Journal Name: International Journal of Biological Macromolecules

Author Name: Rahul Thakur

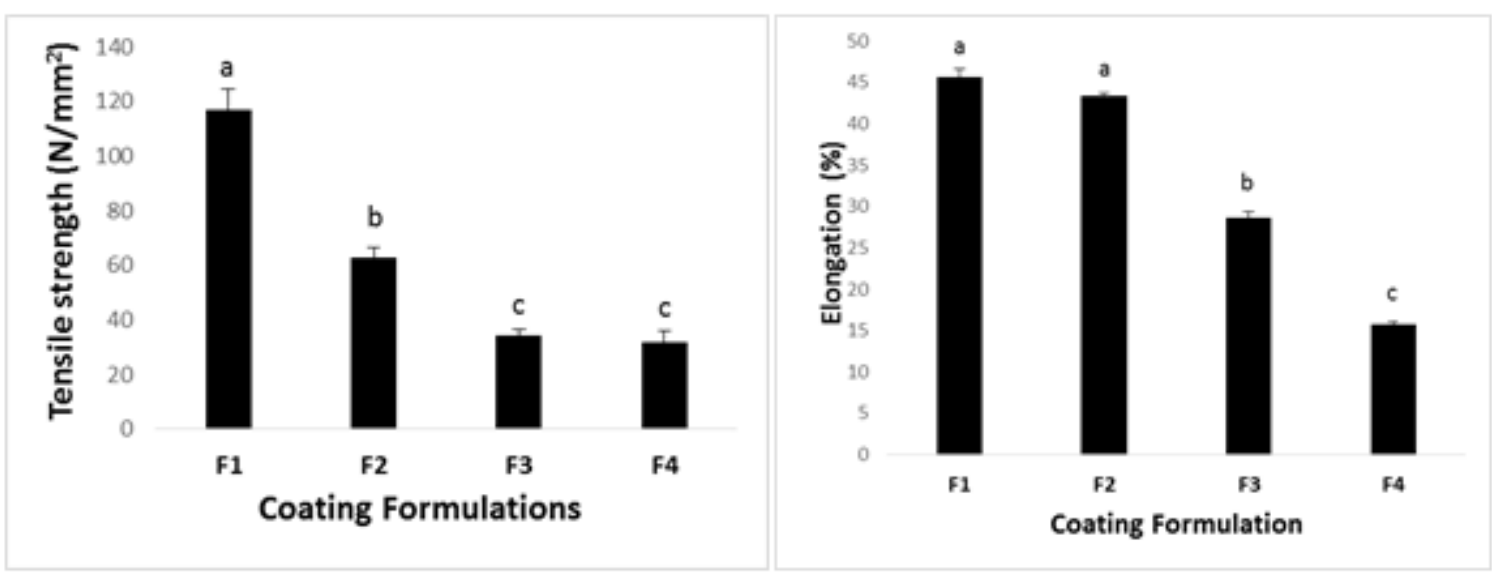

(a)

(b)

Fig. 6 (a, b) 


\section{Table 1}

The different coating formulations containing rice starch (RS), t-car (CR), stearic acid (SA), glycerol (Gly) and Tween ${ }^{\circledR} 20$ used for the experiments.

\begin{tabular}{ccccc}
\hline Variables & \multicolumn{4}{c}{ Formulations (F) } \\
\cline { 2 - 5 } & $\mathbf{F 1}$ & $\mathbf{F 2}$ & $\mathbf{F 3}$ & $\mathbf{F 4}$ \\
\hline RS (\% w/w) & $2 \%$ & $2.50 \%$ & $3 \%$ & $4 \%$ \\
CR (\% w/w) & $2 \%$ & $1.50 \%$ & $1 \%$ & $0.50 \%$ \\
SA (\% w/w) & $0.30 \%$ & $0.50 \%$ & $0.70 \%$ & $0.90 \%$ \\
Gly (\% w/w) & $30 \%(\mathrm{w} / \mathrm{w})$ & $30 \%(\mathrm{w} / \mathrm{w})$ & $30 \%(\mathrm{w} / \mathrm{w})$ & $30 \%(\mathrm{w} / \mathrm{w})$ \\
Tween $^{\circledR} \mathbf{2 0}(\% \mathbf{w} / \mathbf{w})$ & $0.20 \%$ & $0.20 \%$ & $0.20 \%$ & $0.20 \%$ \\
\hline
\end{tabular}




\section{Table 2}

Colour and moisture content of rice starch-1-car film blended with fatty acid, glycerol and surfactant.

\begin{tabular}{cccccc}
\hline $\begin{array}{c}\text { RS: CR: FA: } \\
\text { Gly: Tween }{ }^{\circledR 20} \\
\text { (\% w/w) }\end{array}$ & L & a & b & $\Delta \mathbf{E}$ & Moisture \\
\hline Formulations & & & & & \\
\hline F1 & $95.52 \pm 0.25^{\mathrm{a}}$ & $-0.31 \pm 0.00^{\mathrm{b}}$ & $5.03 \pm 0.25^{\mathrm{b}}$ & $5.33 \pm 0.2^{\mathrm{a}}$ & $8.48 \pm 0.571^{\mathrm{b}}$ \\
F2 & $96.227 \pm 0.32^{\mathrm{a}}$ & $-0.16 \pm 0.01^{\mathrm{a}}$ & $4.31 \pm 0.03^{\mathrm{c}}$ & $5.09 \pm 0.01^{\mathrm{a}}$ & $9.51 \pm 1.56^{\mathrm{b}}$ \\
F3 & $95.448 \pm 0.40^{\mathrm{a}}$ & $-0.36 \pm 0.08^{\mathrm{b}}$ & $6.34 \pm 0.19^{\mathrm{a}}$ & $6.49 \pm 0.0^{\mathrm{b}}$ & $17.06 \pm 0.21^{\mathrm{a}}$ \\
F4 & $95.897 \pm 0.06^{\mathrm{a}}$ & $-0.37 \pm 0.00^{\mathrm{b}}$ & $4.92 \pm 0.10^{\mathrm{b}}$ & $5.43 \pm 0.02^{\mathrm{a}}$ & $11.00 \pm 0.64^{\mathrm{b}}$ \\
\hline
\end{tabular}

- Values denotes the Means of replicates \pm Standard error.

- $\quad{ }^{a-c}$ represents the difference between mean values. The values with the same letter are not significantly different according to Duncan's multiple range test ( $\mathrm{p}>0.05)$. 